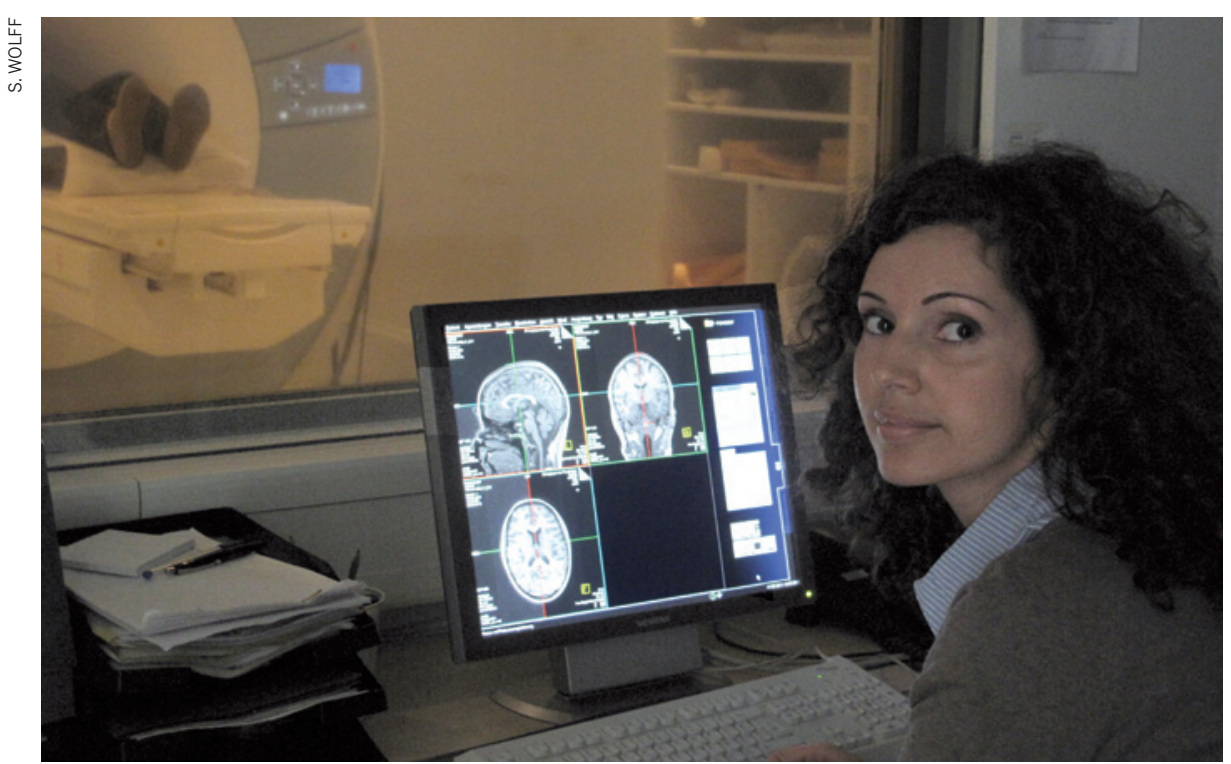

At a research institute in Mannheim, Leila Haddad scolds subjects to stress them while imaging their brains. NEUROSCIENCE

\title{
City living marks the brain
}

\section{Neuroscientists study social risk factor for mental illness.}

\section{BY ALISON ABBOTT}

$\mathrm{E}$ pidemiologists showed decades ago that people raised in cities are more prone to mental disorders than those raised in the countryside. But neuroscientists have avoided studying the connection, preferring to leave the disorderly realm of the social environment to social scientists. A paper in this issue of Nature represents a pioneering foray across that divide.

Using functional brain imaging, a group led by Andreas Meyer-Lindenberg of the University of Heidelberg's Central Institute of Mental Health in Mannheim, Germany, showed that specific brain structures in people from the city and the countryside respond differently to social stress (see pages 452 and 498). Stress is a major factor in precipitating psychotic disorders such as schizophrenia.

The work is a first step towards defining how urban life can affect brain biology in a way that has a potentially major impact on society - schizophrenia affects one in 100 people. It may also open the way for greater cooperation between neuroscientists and social scien-

ONATURE.COM

For more on the

environment and the

brain, see:

go.nature.com/ibdich tists. "There has been a long history of mutual antipathy, particularly in psychiatry," says sociologist Craig Morgan at the Institute of Psychiatry in
London. "But this is the sort of study that can prove to both sides that they can gain from each others' insights."

Meyer-Lindenberg works on risk mechanisms in schizophrenia, and previously focused on the role of genes. But although a dozen or so genes have been linked to the disorder, "even the most powerful of these genes conveys only a $20 \%$ increased risk", he says. Yet schizophrenia is twice as common in those who are city-born and raised as in those

\section{DOSE RESPONSE?}

A 2001 study in Denmark showed that people who grew up in larger cities had a higher risk of schizophrenia.

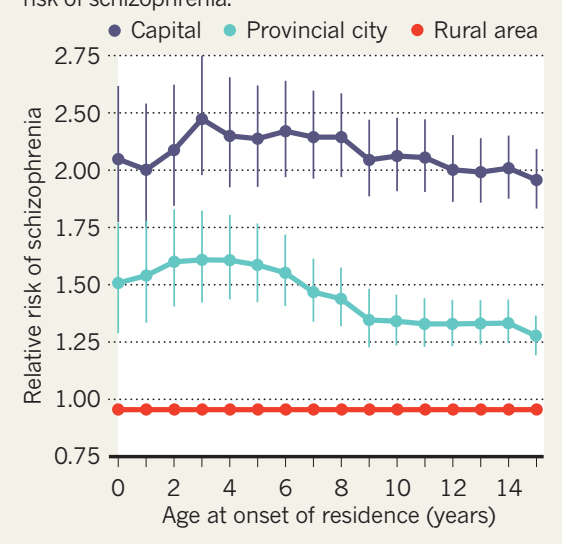

from the countryside, and the bigger the city, the higher the risk (see 'Dose response?').

So Meyer-Lindenberg set out to study how city life might increase the risk of mental illness. The team scanned the brains of 32 student volunteers while they performed arithmetic tests. At the same time, the students received negative feedback through headphones. "We'd tell individuals they were performing below average, and suggest impatiently they hurry up a bit, so they'd feel they were failing," he explains.

This 'social stress' activated many brain areas, two of them specifically correlated with the volunteers' history of urban living. The amygdala, which processes emotion, was activated only in people currently living in a city. And the cingulate cortex, which helps to regulate the amygdala and processes negative emotions, responded more strongly in those brought up in cities than in those who grew up in towns or rural areas.

The initial experiment showed such clear associations that Meyer-Lindenberg didn't think anyone would believe them. So he did a similar experiment on another 23 subjects, this time adding visual feedback that allowed participants to see the investigators' frowns. $\mathrm{He}$ found the same sturdy associations.

He now plans to repeat the work in the general population, where urban-rural differences are likely to be even stronger than in students. $\mathrm{He}$ also plans to study how other risk factors identified by social scientists - such as being an immigrant - affect stress processing. "We will use tools from social scientists to help us quantify things like perceived discrimination, social support networks, or stigma," he says.

Yet he has had trouble interesting his socialscience colleagues in setting up joint projects. Such lack of sympathy across the cultural divide is common, says Ernst Fehr, an economist at the University of Zurich, Switzerland and a pioneer in the field of neuroeconomics, which studies the neurological basis of economic decisions. "But social problems have neurobiological effects, which, in turn, may exacerbate the social problems," he says.

The social sciences have as much to gain from crossing disciplinary boundaries as the biological sciences, says Morgan. "Sociologists and epidemiologists establish associations that are plausible - like immigrants may suffer more mental illness because of social isolation - but they are validated when neuroscientists demonstrate a robust biological mechanism."

For his future investigations, Meyer-Lindenberg is seeking urban planners who can help him to tease out how variables such as green space and population density contribute to the neurobiological impact of city living. Hans Wirz of the urban planning office in Basel, Switzerland, says that it took decades to integrate knowledge about the biomedical effects of the cityscape into his profession. "But when it comes to mental health we haven't a clue." - 